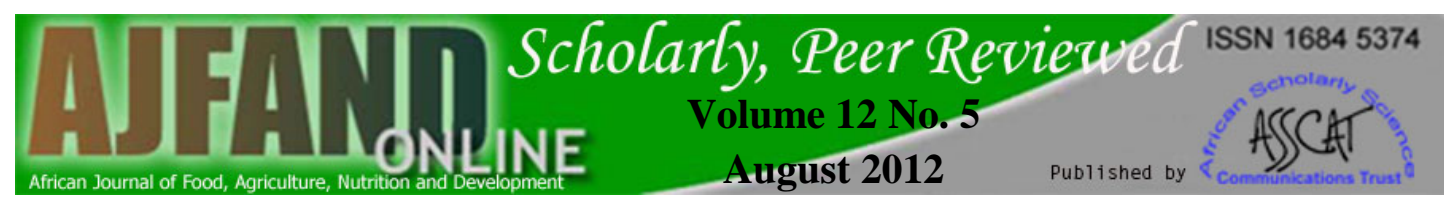

AN ASSESSMENT OF THE PHYSIOLOGICAL QUALITY OF SORGHUM (Sorghum bicolor L Moench) SEEDS PLANTED BY FARMERS IN BOMET DISTRICT OF KENYA

\title{
Ochieng $\mathrm{LA}^{1} *$, Mathenge $\mathrm{PW}^{2}$ and Muasya $\mathbf{R}^{3}$
}

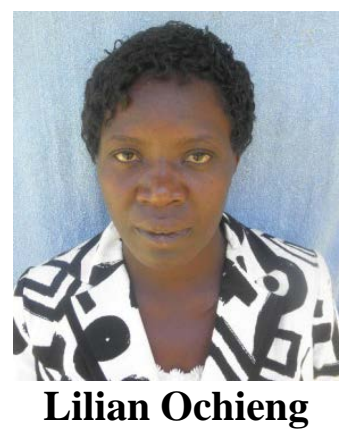

*Corresponding author email: liloochieng@yahoo.com

${ }^{1}$ School of Agriculture, Karatina University College, P.O. Box 1957-10101, Karatina, Kenya.

${ }^{2}$ School of Agriculture, Karatina University College, P.O. Box 1957-10101, Karatina, Kenya.

${ }^{3}$ School of Agriculture Science and Veterinary ciences, Southern Eastern University College, P.O. Box 170-90200, Kitui, Kenya. 


\section{ABSTRACT}

Sorghum (Sorghum bicolor L. Moench) is an important crop that enhances food security in a region. As a food crop, sorghum is nutritious, containing starch (75-79\%) as the major component, followed by protein (6.0-16.1\%) and oil (2.1-5.0\%). Despite the crop's versatility, it is regrettable that sorghum yields are still fairly low in Bomet District of Kenya. One of the constraints associated with low yields is the accessibility to good quality seeds by farmers. It was assumed in this study that use of low quality seed was among the factors that could be significantly affecting the low production of sorghum in the district. This study focused on the physiological quality of seed which refers to the germination capacity, viability, characteristics related to dormancy and vigour of the seed. A total of 100 farmers were interviewed and 80 seed samples were obtained from 80 farmers. The seeds were subjected to viability and vigour quality tests. These tests included germination (as a viability test); mean germination time and electrical conductivity tests (as vigour tests). About $29 \%$ of the seed samples taken for germination test were below the laboratory standards as stipulated in the seeds and Plant Varieties Act (CAP 326). Critical electrical conductivity values and critical mean germination time values were derived during the study. In accordance with the critical values arrived at in this study, $27.5 \%$ of the seed samples showed relatively high electrical conductivity readings and $36.3 \%$ of the seed samples showed longer mean germination time. However, $11.3 \%$ of the seed samples showed high germination percentages of above $90 \%$. Since about $29 \%$ of farmers seeds were of bad physiological quality, it was concluded that this proportion of seed can result in poor yields and hence cause food insecurity to the people of the society, and thus requires further consideration for improvement. This study recommends that further research be conducted on the genetic, physical and sanitary quality aspects of seed planted by farmers in Bomet District so that a definite conclusive statement about the quality of seed planted by farmers in the District can be made.

Key words: sorghum, viability, vigour, germination, quality. 


\section{INTRODUCTION}

Sorghum is one of the world's major food crops, particularly in areas of low and unreliable rainfall such as in arid and semi-arid regions [1, 2]. In Kenya, sorghum is ranked third after maize and wheat as a food crop [3]. Bomet District of Kenya is characterized by harsh environmental conditions like low and unreliable rainfall. Farmers in these low production zones need to grow drought tolerant crops like sorghums, finger millets and cassava if poverty has to be alleviated [4]. Sorghum production in Bomet District is low [5].

Majority (98\%) of sorghum small-scale farmers in Bomet District depend on the informal seed supply systems for their seed [6]. The informal seed supply system is comprised of systems such as retaining seed on-farm from previous harvests to plant in the following season and farmer-to-farmer seed exchange networks [7, 8]. On-farm seed is produced and managed by farmers themselves. The resultant seed quality of on-farm produced seed depends on how well the seed crop was managed from land preparation stage to harvest stage; how seed was threshed from the panicles; and seed storage methods. Some of on-farm produced seed are at times of low quality. About $30 \%$ of the seed produced by farmers in Kenya are poor quality due to the use of poor quality seed for planting, assuming all other factors are favourable [9].

Quality seed is one of the primary requirements for establishing food security to farmers. Seed quality of a given seed lot is the degree of excellence of that seed when compared to acceptable standards. Good quality seed meets the required biological, physical, physiological (viability and vigour), genetic and pathological standards set by quality control agencies [10]. Only quality seed can reproduce well and preserve the future generation without deviating from the original seed properties [11]. Apart from the genetic, analytical, physiological and health status of a seed, other seed quality characteristics include moisture content, maturation, size and colour. Guaranteeing farmers access to quality seed can only be achieved if there is an efficient seed production and supply system in multiplication and distribution. Enhanced productivity, reduced risks from pest and disease pressure, higher harvest index, and higher incomes are some of the direct benefits potentially accrued to farmers through the use of good quality seed.

Seed viability in this context refers to the capability of a seed to germinate and produce a "normal seedling" [12]. Seed vigour is "those seed properties which determine the potential for rapid, uniform emergence, and development of normal seedlings under a wide range of field conditions" [13]. Hence a seed may be viable but not of high vigour. Standard germination is a universally applicable test on various crops and is used to determine seed viability. Standard germination test alone is not adequate to indicate quality attributes of seed because it only indicates the ability to produce normal seedlings in ideal conditions [14]. Therefore, an additional test such as seed vigour may complement germination test. A universally applicable, single vigour test for multiple crop types has not yet been identified. There are several vigour tests such as tetrazolium, electric conductivity, speed of germination, seedling growth rate, accelerated aging, brick grit, and cold tests [12]. Nutrient leaching from

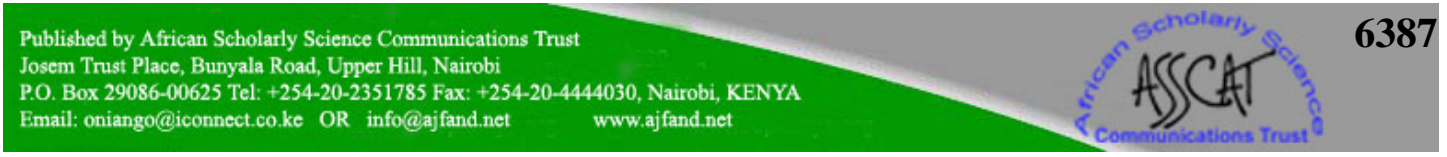


damaged or aged seeds formed the basis for conductivity vigour tests with a variety of seed types [15]. Weak seeds can possess poor membrane structure, which results in greater electrolyte loss and higher conductivity measurements in the imbibing solution. Seed deterioration contributes to loss of vigour and eventually germination [16].

The objective of this study was therefore to assess the quality (viability and vigour) of sorghum seeds planted by small-scale farmers in Bomet District of Kenya.

\section{MATERIALS AND METHODS}

A total of 100 farmers were interviewed during a field survey in Bomet District, in June and July, 2005 and in the process each farmer was requested to provide a sample of $250 \mathrm{~g}$ of threshed seed which she/he was just about to plant in the next season (which was beginning from December 2005 to January 2006). As such, 80 seed samples were collected from 80 farmers, put in moisture proof bags (polythene bags) and labeled (from label 1 to label 80) and taken to Eldoret for laboratory testing. The moisture content of the samples was about $12 \%$ stored in a refrigerator at $2-5{ }^{\circ} \mathrm{C}$ awaiting laboratory analysis. The laboratory experiments included germination, mean germination and electrical conductivity tests. The labeling for each sample remained consistent in all these tests.

\section{Laboratory experiments}

\section{Determination of germination percentage of sorghum seeds (Standard germination test)}

Germination test was done according to International Seed Testing Association rules (ISTA) [17]. Four hundred seeds were counted at random from each of the 80 seed samples collected from farmers. The 400 seeds from each sample were grouped into four replicates. The four replicates (each of 100 seeds) were then sterilized in one percent sodium hypochlorite for ten minutes to reduce infection on the seed surface by micro-organisms and also to recondition the seeds to stimulate germination. Filter papers were moistened with distilled water and put in transparent sterlin Petri dishes (each Petri dish contained three moistened filter papers). The filter papers were the substrates on which seeds were grown. One hundred seeds of each of the four replicates were arranged on top of the filter papers in Petri-dishes, and then the Petridishes were covered tightly with fitting lids. The Petri-dishes were then put in a germination cabinet at $25{ }^{\circ} \mathrm{C}( \pm 5)$ that illuminated light in the whole period of the test. The first count of emergent seedlings was taken on the fourth day and the final count and seedling evaluation were done on the tenth day. Seedlings were evaluated as normal seedlings; abnormal seedlings; hard seeds; rotten seeds; or diseased seedlings in accordance with the instructions given in the ISTA rules [17]. The percent germination was determined by the proportion of normal seedlings on the tenth day. 


\section{Determination of critical/standard mean germination time of sorghum seeds (Speed of germination test)}

The speed of germination test was done on the premise that, seeds high in vigour would produce more seedlings within the first few days after sowing as compared to the seeds that are low in vigour. Initially, the critical mean germination time was determined, followed by the actual determination of mean germination time of the 80 seed samples collected from 80 farmers. The critical mean germination time derived from this test was the standard value used to rate good quality and bad quality seed.

In the determination of the critical mean germination time of sorghum seeds, two samples from different sources were used. One sample of sorghum seeds was obtained from Kenya Agricultural Research Institute (KARI), Lanet and another sample from a farmer's store. The seed from KARI was considered to be a standard of good quality seed because of its good storage conditions while the farmer's seed was considered to be a standard of poor quality seed as some of the seeds were infested by weevils due to the poor storage conditions. Four replicates of 25, 50, 75 and 100 seeds (of both good and poor quality seed samples) were subjected to speed of germination test. The seeds were counted at random from the two seed lots. The four replicates (each of the 25, 50, 75 and 100 seeds) from each of the two seed lots were then sterilized in one percent sodium hypochlorite for ten minutes to reduce infection by micro-organisms in accordance with ISTA [17]. Filter papers were moistened with distilled water and put in transparent sterlin Petri dishes (each Petri dish contained three moistened filter papers). The filter papers were the substrates on which seeds were grown. The seeds of each of the four replicates were arranged on top of the filter papers, and then the Petri-dishes covered tightly with fitting lids. The Petri-dishes were then put in a germination cabinet at $25{ }^{\circ} \mathrm{C}( \pm 5)$ with light illumination for the whole period of the test in accordance with ISTA [17]. The count of emerged seedlings in each Petri-dish was taken on a daily basis (after every 24 hours) until the tenth day from the sowing date. The mean germination time was then calculated using the following method [18]

Mean germination time $=\underline{\Sigma(\mathrm{fx})}$

$$
\Sigma(\mathrm{f})
$$

Where: $f$ is the number of newly germinated seeds at a given time. $\mathrm{x}$ is the number of days or hours counted from the day of sowing.

The critical mean germination time of sorghum seeds derived from this study was two days. The critical number of seeds to be counted per sample derived from this study was 100 seeds. The assumption made in this study was that since all good quality seed samples (samples from KARI) took less than two days to germinate, any seed lot that took more than two days to germinate was considered to be of poor vigour. Also, 100 seeds of both good and bad quality gave more stable results as compared to 25, 50 or 75 seeds.

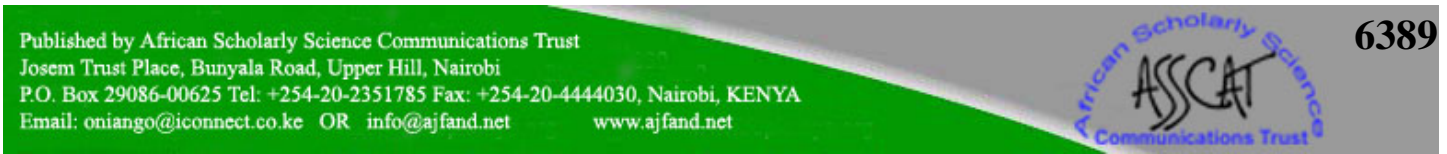




\section{Determination of mean germination time of sorghum seeds}

Having determined the critical mean germination time as described above (two days), it meant that any sample that was going to take more than two days to germinate was automatically rated as low quality seed. More so, the critical number of seeds to be counted per sample derived as 100 seeds was used in this test. As a result, the determination of the mean germination time of the 80 seed samples collected from 80 farmers was done by following the whole procedure as that which was used in the determination of the critical values except that in this case, experiments on the samples of 25, 50 and 75 seed counts were not carried out. Instead, only four replicates of 100 seeds were counted at random from the seed lots of each collected sample.

\section{Determination of the critical (standard) electrical conductivity value of sorghum seeds}

Electrical conductivity test was done to complement the results obtained during the performance of the mean germination time test. In the determination of the electrical conductivity critical value of sorghum seeds, two samples were collected from two different sources. One sample of sorghum seeds was obtained from KARI, Lanet and another from a farmer's store. The seed from KARI was a standard to be of good quality because of its good storage conditions while the farmer's seed was considered to be of poor quality since it was infested by weevils due to the poor storage conditions. The moisture content of both samples was determined by air oven method and the samples were then subjected to the electrical conductivity test. From each of the two samples four replicates of 25, 50, 75 and 100 seeds were counted at random and weighed to three decimal places before being soaked in $250 \mathrm{ml}$ - distilled water in plastic containers at $20{ }^{\circ} \mathrm{C}$ in an incubator. Also, four replicates of 25, 50, 75 and 100 seeds in $200 \mathrm{ml}$ - distilled water; $150 \mathrm{ml}$ - distilled water; $100 \mathrm{ml}$ - distilled water; and $50 \mathrm{ml}$ - distilled water were set up in the same way. The plastic containers with seeds and distilled water were covered with aluminium foil to reduce evaporation and avoid contamination by dust. A container with distilled water only and covered with aluminium foil was set up with each test run as the control. All the containers were labeled and maintained at $20{ }^{\circ} \mathrm{C}$ for 24 hours. After 24 hours, the solutions and seed in each container were gently swirled for $10-15 \mathrm{sec}$., and conductivity $\left(\mu \mathrm{S} \mathrm{cm}{ }^{-1}\right)$ of the soak water was measured using Fieldlab - LF conductivity meter (Schott Gerate Glass Company, Mainz, Germany). Several measurements were taken until a stable electrical conductivity reading was obtained on the conductivity meter. Between measurements, the dip cell was rinsed twice in distilled water and dried using clean dry paper towels. After subtracting the control measurement (the mean of the readings), conductivity was expressed as per gram of seed $\left(\mu \mathrm{S} \mathrm{cm}^{-1} \mathrm{~g}^{-1}\right)$. The conductivity values were calculated as:

Conductivity $\left(\mu \mathrm{S} \mathrm{cm}^{-1} \mathrm{~g}^{-1}\right)=\underline{\left.\text { conductivity reading }\left(\mu \mathrm{S} \mathrm{m}^{-1}\right)-\text { background reading }(\mu \mathrm{S} \mathrm{cm})^{-1}\right)}$ Weight (g) of replicate

The critical levels of water and seeds for sorghum were determined depending on the quality of the results (that is, the level of water and seed that gave averagely low electrical conductivity readings for both poor and good quality seed) was chosen to be

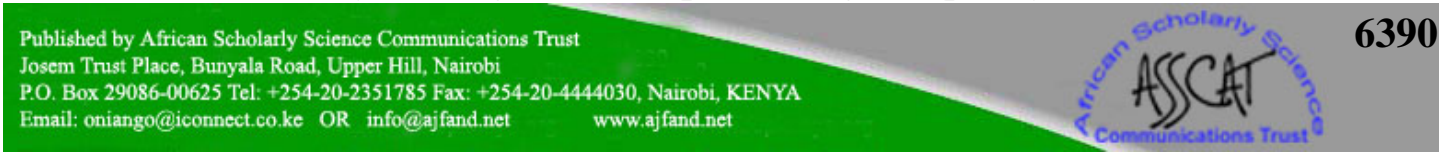


used as a standard in the rest of this study. From the results, the critical levels of the seeds and water were 100 seeds and $250 \mathrm{mls}$ respectively. The critical electrical conductivity value for sorghum derived from this study was $0.90 \mu \mathrm{Sm}^{-1} \mathrm{~g}^{-1}$. The assumption made in this study was that the good quality seed samples were about three times better than the poor quality seeds.

Having determined the electrical conductivity critical (standard) value, it meant that any sample that was going to have a conductivity of $>0.90 \mu \mathrm{S} \mathrm{cm}{ }^{-1} \mathrm{~g}^{-1}$ was automatically rated as low quality seed. More so, the critical number of seeds to be counted per sample derived (100 seeds), was used in this test.

\section{Determination of electrical conductivity of sorghum seeds}

The determination of the electrical conductivity of the 80 seed samples collected from 80 farmers was done following the whole procedure used in determining the electrical conductivity critical value with the exception of not including experiments on replicates of 25, 50 and 75 count seeds. Therefore, four replicates of 100 seeds were counted at random from each collected seed sample instead of drawing four replicates of $25,50,75$ and 100 seeds.

\section{RESULTS}

\subsection{Germination percentage of sorghum seed samples collected from farmers in Bomet District of Kenya}

About $11.3 \%$ of the seed samples had more than $90 \%$ germination (Figure 1). About 28.8\% percent (bars with letter "b" in Figure 1) of the seed samples had a germination capacity of less than the minimum germination percentage of $70 \%$ as stipulated in the Seeds and Plant Varieties Act CAP 326 of the laws of Kenya [19]. Of the seed samples collected, 71.4\% (symbolized by letter “a” in Figure 1) met the critical minimum germination rate stipulated in the Seeds and Plant Varieties Act CAP 326 of the laws of Kenya [19]. 

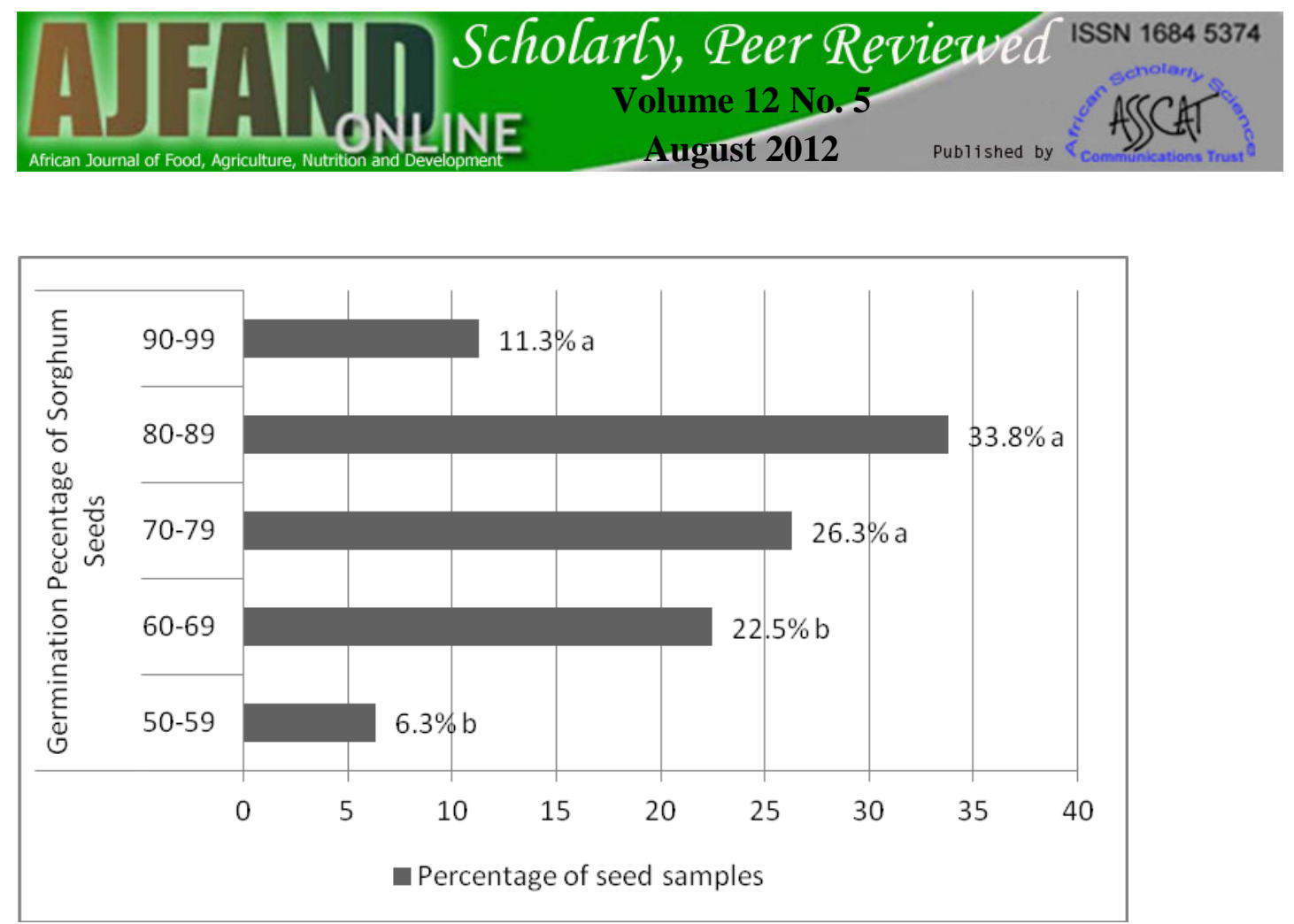

Figure 1: Germination Percentage of Sorghum Seed Samples Collected from Farmers in Bomet District

2.0 Electrical conductivity of sorghum seed samples collected from farmers in Bomet District of Kenya

About $72.5 \%$ of seed samples (symbolized by letter "a" in Figure 2) gave an average electrical conductivity reading of $\leq 0.90 \mu \mathrm{S} \mathrm{cm}^{-1} \mathrm{~g}^{-1}$ while $27.5 \%$ (symbolized by letter "b" in Figure 2) gave a reading $>0.90 \mu \mathrm{S} \mathrm{cm}^{-1} \mathrm{~g}^{-1}$. About $12.5 \%$ of seed samples had high electrical conductivity readings of $>1.00 \mu \mathrm{Sm}^{-1} \mathrm{~g}^{-1}$ (Figure 2).

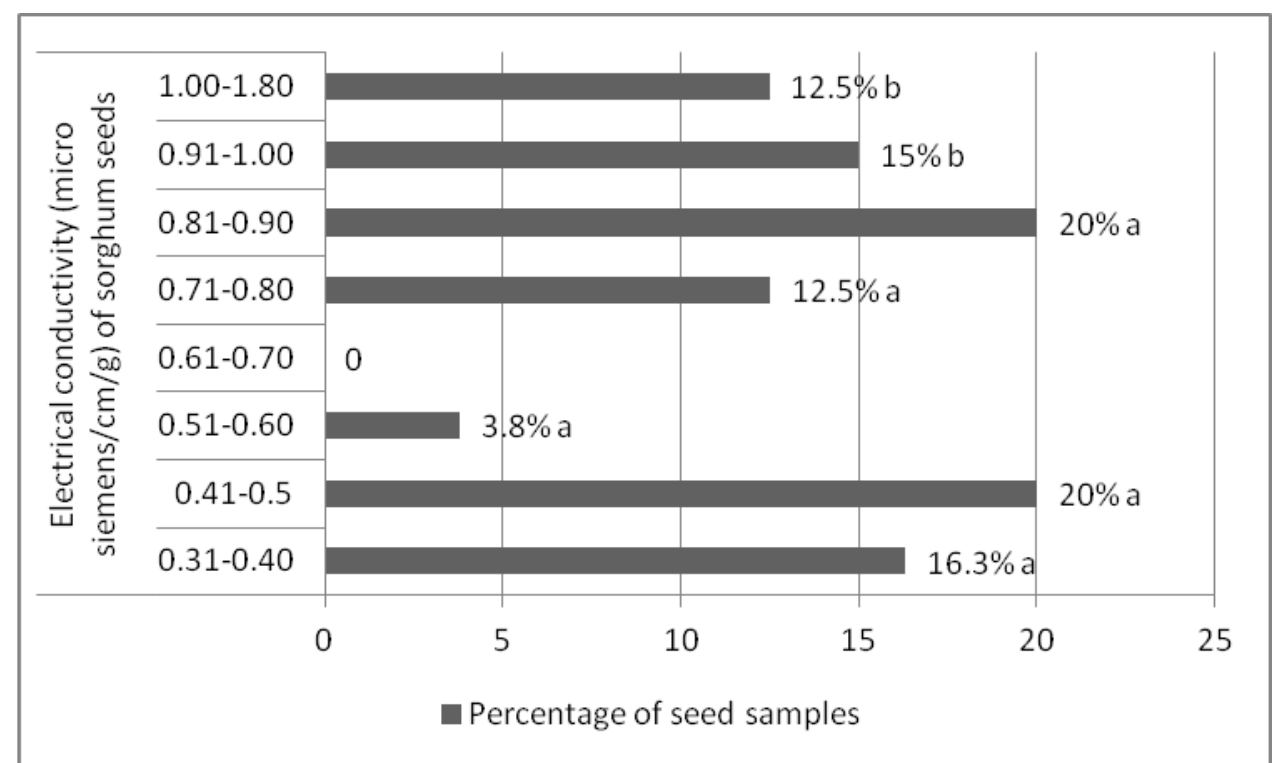

Figure 2: Electrical Conductivity (micro siemens/cm/g) of Sorghum Seed Samples Collected from Farmers in Bomet District 


\subsection{Mean germination time of sorghum seed samples collected from farmers in Bomet district of Kenya}

Of the seed samples taken for laboratory testing 36.3\% (symbolized by letter "b" in Figure 3) had a mean germination time of more than two days. About $63.8 \%$ (symbolized by letter "a” in Figure 3) of the seed samples took $\leq 2$ days to germinate. Of the seed samples taken for mean germination time test, two and a half percent took more than two and a half days to germinate (Figure 3).

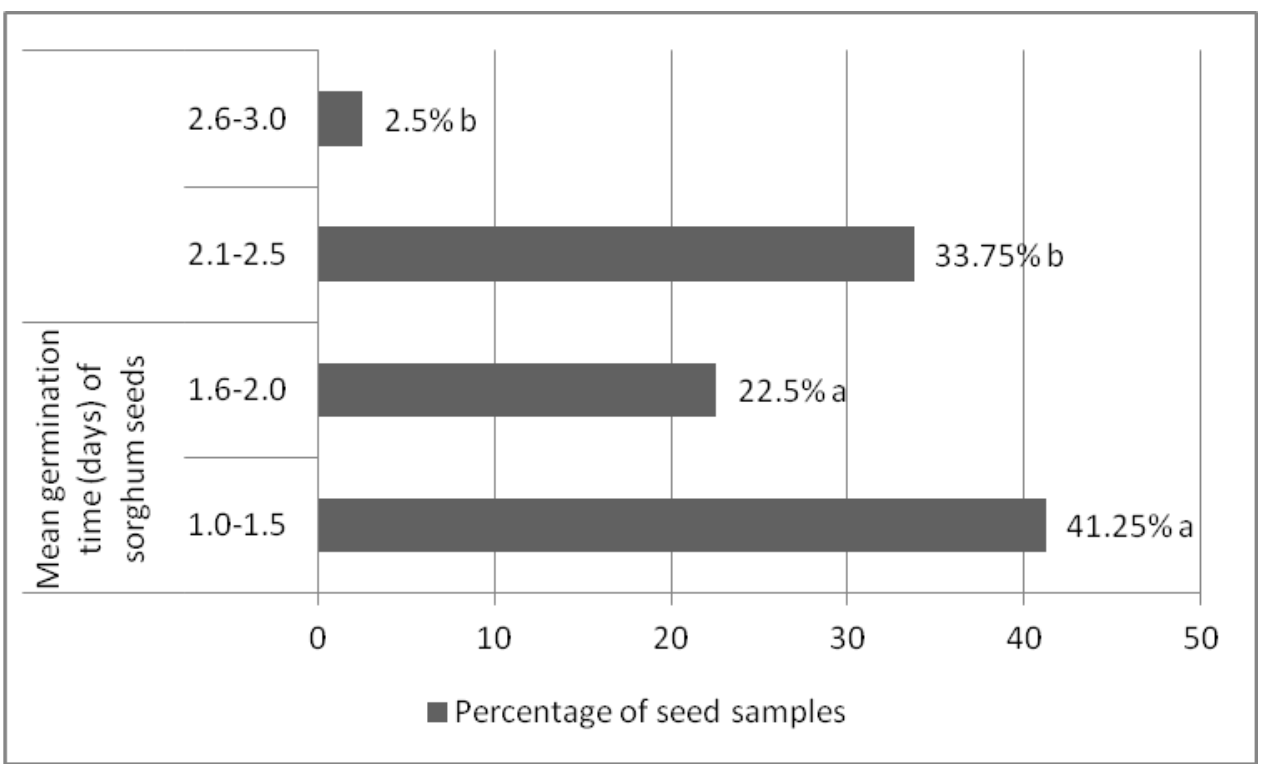

Figure 3: Mean Germination Time (days) of Sorghum Seed Samples Collected from Farmers in Bomet District.

\section{DISCUSSION}

Germination is the emergence and development from the seed embryo of those essential structures which are indicative of the ability to produce a normal plant under favorable conditions [13]. The "essential structures" are the root and shoot axes, cotyledons, terminal buds and the coleoptiles. Field emergence ability is a major aspect of seed quality of concern to growers [20] and high germination is a prerequisite for seed to be sown, whether it is to be used to further multiply seed, provide pasture for grazing animals or provide seed for crop production. The results of this study show that less than three quarters of seeds produced by farmers are of good quality in this aspect and therefore viable. Nonetheless, if more than one quarter of seeds planted by farmers is not viable, then this poses a threat to food security in the region and should be an area of concern. More so, it is not usually true that all seedlots exceeding "the critical minimum germination" are equally good in the eventual test of quality and emergence in the field [21, 22]. This is because, the lower the germination, the poorer the performance since deterioration has occurred [23] even though all lots met the minimum germination recommendation. While it is sometimes possible to compensate for reduced germination by increasing sowing rates so as to achieve a desired population as practiced by many farmers in the District [6], a point is reached where there can be deleterious effects on yield and quality [24].

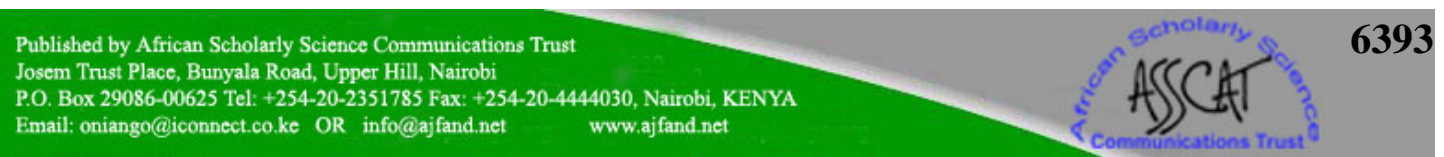


Loss of viability as expressed by the $29 \%$ of seeds might have probably resulted from deterioration processes involved with pre-harvest and post-harvest seed aging [25].

Numerous studies have demonstrated the presence of membrane degradation in seeds of low vigour [15, 26, 27, 28]. Physiological processes involving membranes or membrane-bound proteins such as ATP, RNA, protein synthesis or respiration are inhibited by non-functional membranes [14]. The low vigour (36.3\%) indicated by the speed germination test is probably due to the inhibition of the proper functioning of the membranes or the membrane-bound proteins, thus resulting in the slow germination of seedlings in the first days of the test. The results that low quality seed (from the speed of germination test) are high (36.3\%) as compared to the percentage obtained from germination test (29\%) is acceptable since seed vigour precedes seed viability [16]. However, the results that a lower percentage of seed samples (27.5\%) were of poor quality (in relation to electrical conductivity test) as compared to the germination test (29\%) requires further investigation especially in the determination of the right protocol of performing the conductivity test. This is because seed deterioration contributes to a loss of vigour and eventually germination [16]. However, the error could have been brought about by the type of conductivity meter used in the experiment whereby it could only allow seeds to be tested in a bulk of 100 seeds. This usually results in the assumption that all tested seeds have the same vigour, which is not true [14]. Currently, an instrument has been developed that possesses the capability of monitoring individual seed conductivity values, and this gives more reliable results.

\section{CONCLUSIONS AND RECOMMENDATIONS}

The results of this study show that more than one quarter of sorghum seeds used by farmers to plant their crop is clearly of inadequate quality in relation to germination and vigour tests performed. This proportion of seed with inadequate quality does represent a risk for loss of valuable genotypes [11] and can lead to poor crop yield in the future when seeds of such inferior quality continue to be regenerated. Therefore, there is a need to improve this proportion of low quality seeds produced by farmers. Seed quality is comprised of more quality aspects than those analyzed in this study and, therefore, it is recommended that further research be done on the sanitary, analytical and genetic aspects of the sorghum seeds planted by farmers in Bomet District to enable the clarification of the extent to which seed quality affects crop production. It is also recommended that more seed vigour tests be performed on sorghum seeds so as to standardize the protocols that seed growers should follow in determining the vigour test.

\section{ACKNOWLEDGEMENT}

The authors acknowledge with thanks to farmers who participated in the survey in Bomet District for their time and sharing their knowledge and ideas. Logistical support by Moi University is also greatly acknowledged.

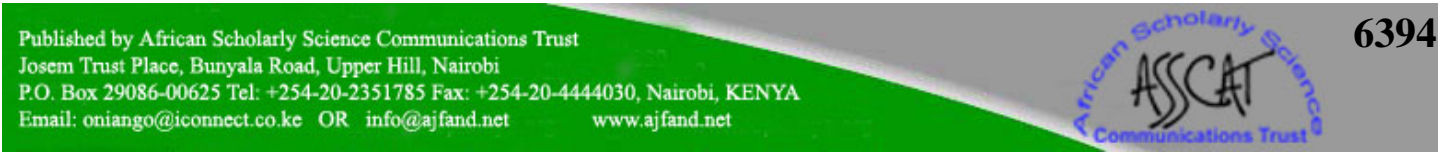




\section{REFERENCES}

1. Kenya Agriculture Research Institute Pasture and Sorghum Production. In: Ashiono G, Changwony K, Muriithi G and D Indetie, (Eds). Technical Hand Book for Boran, Nairobi, Kenya, 2003:56

2. Wanyama JM, Njue EK and NL Kidula. Evaluation of Sorghum Technology Adaptation Levels in Homa Bay District. In: Fungoh PO and GCO Mbadi (Eds). Focus on Agricultural Research for Sustainable Development in a Changing Economic Environment. Homa Bay, Kenya, 1996.

3. Kenya Agriculture Research Institute Medium Term Plan, 2002.

4. Ministry of Agriculture, District Farm Management Annual report, Bomet District of Kenya, 2004.

5. Government of Kenya, Bomet District Development Plan (2003-2008). Ministry of Home Affairs and National Planning, 2006.

6. Ochieng LA, PW Mathenge and R Muasya A survey of on-farm seed production practices of sorghum (Sorghum bicolor L.) in Bomet District of Kenya. African Journal of Food, Agriculture, Nutrition and Development 2011. Vol. 11(5): 5232-5253

7. Cromwell E, Friis-Hansen E and M Turner The Seed Sector in Developing Countries: A Framework for Performance Analysis. Working Paper 65, Overseas Development Institute, London, 1992.

8. Lanteri S and L Quagliotti Problems Related to Seed Production in the African Region. Euphytica 1997; 96: 173-183.

9. Combes RG Why are GLP Seeds Not Planted More Often? Kenya Farmer, August, 1983:26.

10. Douglas J Successful Seed Programs. A Planning and Management Guide. Boulder, Colorado, Westview Press, 1980:46-53.

11. Hong TD, Linigton $\mathbf{S}$ and RH Ellis Seed Storage Behaviour; A Compendium. Handbooks for Gene Banks: No. 4. IPGRI, Rome, 1996.

12. Dornbos David L (Jr) Seed Vigor. In: Basra AS (Ed). Seed Quality "Basic Mechanisms and Agricultural Implications.” New York: Food Products Press, 1995:45-80

13. Association of Official Seed Analysts Rules for Testing Seeds. Journal of Seed Technology.12:1-109

14. Copeland LO and MB McDonald Seed Science and Technology ( ${ }^{\text {rd }}$ Edition). New York: Chapman \& Hall, 1995: 111-126 and 153-180 
15. McDonald MB (Jr) A Review and Evaluation of Seed Vigor Tests: Proceedings of the Association of Official Seed Analysts, 1975; 65:109-139.

16. Agrawal PK Seed Storage and Packaging. In: Gastel van AJG and J Kerley (Eds). Quality Seed Production. ICARDA, Aleppo, 1986:55-72

17. International Rules for Seed Testing (ISTA), Basserdorf, Switzerland, 2004.

18. Nicols MA and A Heydecker Proceedings of the International Seed Testing Association, 1968; 33: 531-540.

19. The Constitution of Kenya "The Seeds and Plant Varieties Act, Chapter 326. Revised Edition. 1991:96pp.

20. Pieta FC and RH Ellis The Development of Seed Quality in Spring Barley in Four Environments. A. Germination and Longevity. Seed Sci. Res. 1. 1991:163-177.

21. Delouche JC Harvest and Post-harvest Factors Affecting the Quality of Cotton Planting Seed and Seed Quality Evaluation. Proceedings of Beltwide Cotton Production Research Conference. 1981:289-305

22. Mathews S Evaluation of Techniques for Germination and Vigour studies. Seed Sci \& Technol. 9. 1981:543-551

23. Hampton JG and P Coolbear Potential versus Actual Seed Performance “Can Vigour Performance Provide an Answer?” Seed Sci \& Technol. 18. 1990: 215-228

24. Khah E.M., E.H. Roberts, and R. H. Ellis Effects of seed aging on the growth and yield of spring wheat at different plant population densities. Field Crops Res. 20. 1989: 175-90

25. Powell AA Seed Vigour and field establishment. Adv. Seed Res. And Technol. II. 1988: 25-61

26. Koostra PT and JF Harrington Biochemical Effects of Age on Membranal Lipids of Cucumis sativus L. Seed. Proceedings of International Seed Testing Association 1969. 34: 329-340

27. Villiers TA Aging and the Longevity of Seeds in Field Conditions. In: Heydecker WH (Ed). Seed Ecology. University Park, PA: The Pennsylvania University Press. 1973: 265-288.

28. Stewart RRC andJD Bewley Lipid Peroxidation Associated withAccelerating Aging of Soybean Axes. Plant Physiology 65. 1980: 245249 